\title{
Blood on board: The development of a prehospital blood transfusion program in a Canadian helicopter emergency medical service
}

\author{
Chase Krook, MD, BMSc ${ }^{*}$; Domhnall O’Dochartaigh, RN, MSc, ENC(C), CNCC $(\mathrm{C})^{*}$; Doug Martin, \\ $\mathrm{MD}^{* \neq}$; Zoë Piggott, $\mathrm{MD}^{*^{*}}$; Ryan Deedo, $\mathrm{MD}^{*^{+}}$; Sarah Painter, RN, BN, ENC(C)*; \\ Gennifer van Werkhoven, ACP*; Darcy McKay, ACP, BappBus:ES, MALT*; Dennis Nesdoly, MD*; \\ JN Armstrong, MD*
}

\begin{abstract}
CLINICIAN'S CAPSULE
What is known about the topic?

Emerging evidence regarding prehospital blood transfusions for patients in hemorrhagic shock is positive.

What did this study ask?

Describe the implementation and stewardship of a prehospital blood transfusion program, as well as basic demographics and blood traceability.

What did this study find?

We provided blood transfusion to 274 mainly male trauma patients, and just $1.2 \%$ of units were wasted.

Why does this study matter to clinicians?

Implementation of a similar program at other prehospital organizations can be sustainably achieved.
\end{abstract}

\section{ABSTRACT}

Objective: Prehospital blood transfusion has been adopted by many civilian helicopter emergency medical services agencies, and early outcomes are positive. The Shock Trauma Air Rescue Society operates six bases in Western Canada and started a blood on board process in 2013 in Regina that has expanded to all bases. Two units of $O$ negative packed red blood cells are carried on every mission. We describe the processes and standard work ensuring safe storage, administration, and stewardship of this important resource.

Methods: The packed red blood cells are stored in an inexpensive, reusable temperature controlled cooler at $1^{\circ} \mathrm{C}-6^{\circ} \mathrm{C}$. Close collaboration with local transfusion services and adherence to Canadian transfusion standards contributes to safety and sustainability.

Results: From October 1, 2013 to October 10, 2017, the Shock Trauma Air Rescue Society administered blood to 431 patients. Of this total, $62.9 \%$ received blood carried on our aircraft. A total of 463 blood box units were administered, and the majority of patients $(69.0 \%)$ received both units. Blood used in Calgary, Alberta was $100 \%$ traceable, and only $1.2 \%$ of total units dispensed was wasted. The vast majority of unused units were returned to circulation.

Conclusion: We describe the process to set up and monitor a prehospital blood transfusion program. Our standard work and stewardship processes minimize wastage of blood while keeping it readily available for our critically ill and injured patients.

\section{RÉSUMÉ}

Contexte: Des programmes de transfusions préhospitalières de sang ont été adoptés par de nombreuses agences civiles de services médicaux d'urgence (SMU) par hélicoptère et les résultats préliminaires sont bons. La Shock Trauma Air Rescue Society dirige six bases dans l'Ouest du Canada et a entrepris un service de transport de sang par hélicoptère en 2013, à Régina, service qui a par la suite été élargi à toutes les bases. Deux poches de concentré de globules rouges $O$ négatif sont transportées à chaque mission. Seront présentés dans I'article les processus et le mode habituel de fonctionnement d'une bonne conservation, d'une administration sûre et d'une gestion serrée de cette importante ressource.

Méthode: Les poches de concentré de globules rouges sont conservées dans une boîte isolante abordable et économique, à température réglable entre 1 et $6^{\circ} \mathrm{C}$. Une collaboration étroite avec les services locaux de transfusion et le respect des normes canadiennes de transfusion contribuent à l'innocuité des transfusions et au maintien du programme.

Résultats: La Shock Trauma Air Rescue Society a procédé, entre le $1^{\text {er }}$ octobre 2013 et le 10 octobre 2017, à l'administration de sang à 431 patients et chez 62,9\% d'entre eux celui-ci avait été transporté par I'hélicoptère. Ont été transfusées au

From the *Shock Trauma Air Rescue Society, Calgary, AB; †Department of Emergency Medicine, University of Calgary, Calgary, AB; and ¥Department of Emergency Medicine, University of Manitoba, Winnipeg, MB.

Correspondence to: Dr. Chase Krook, Department of Emergency Medicine, Foothills Medical Centre, C231, 1403 - 29 St. NW, Calgary, AB T2N 2T9; Email: Krook.chase@gmail.com 
total 463 poches de sang et la majorité des patients $(69,0 \%)$ en ont reçu deux. Les poches de sang utilisées à Calgary (Alberta) étaient traçables à $100 \%$ et seuls 1,2 \% des poches délivrées à la Society ont été perdues. La plupart des sacs inutilisés ont été remis en circulation.

Conclusion: A été présenté dans l'article le processus de mise sur pied et de surveillance d'un programme de transfusions préhospitalières de sang. Le mode habituel de fonctionnement et le processus de gestion permettent à la fois de réduire au minimum les pertes de poches de sang et d'offrir rapidement aux personnes gravement malades ou blessées des SMU.

Keywords: helicopter emergency medical services, prehospital blood transfusion, quality assurance

\section{INTRODUCTION}

\section{Background}

In Canada, injury leads to approximately 16,000 deaths per year and is the leading cause of death in people ages 1 to 44 years old. ${ }^{1}$ Hemorrhage remains a leading cause of death in traumatically injured patients. ${ }^{2}$ Early blood transfusion has been shown to improve outcomes in patients with hemorrhagic shock ${ }^{3,4}$ and remains a key tenet of damage control resuscitation. ${ }^{5}$ These improvements may be attributable in part to a reduction in the volume of crystalloid administered when blood is available in a timely manner. Aggressive crystalloid resuscitation is known to cause multiple cellular abnormalities that contribute directly to the deadly triad in trauma patients: hypothermia, acidosis, and coagulopathy. ${ }^{6,7}$

Helicopter emergency medical services (HEMS) utilization provides advanced and timely care to critically ill and injured patients in the prehospital environment. ${ }^{8-10}$ Prehospital blood transfusion has recently been adopted by many civilian emergency medical systems based on successful military employment of this strategy in combat scenarios. ${ }^{11-14}$ A survey of civilian HEMS services in the United States found that 25\% carry prehospital blood products. ${ }^{15}$

We describe the processes and standard work governing safe storage, administration, and stewardship of blood products within a Canadian HEMS organization, as well as initial patient data examining usage, demographics, and outcomes from program inception in October 2013. Blood traceability data from Calgary is presented for ease of data gathering (primary investigator is based at that centre). Quality assurance review data from Winnipeg Base are offered as an example, because they were the final base to implement blood on board and capture learnings from implementation at other bases.

\section{METHODS}

\section{Study design and subjects}

We carried out a health records review as part of ongoing quality assurance initiatives at our centre. Data were retrieved from electronic patient care records (ePCR) for all patients receiving a prehospital transfusion between October 1, 2013 and October 10, 2017. A standardized data collection spreadsheet (Excel, Microsoft) with a priori defined variables was used for data abstraction and analysis. Data abstraction was conducted by two researchers (GVW, SP), each with over 5 years of experience working clinically in HEMS. Data collected included basic demographics, location and type of call, clinical reason for blood administration, and survival to hospital admission. Each abstractor reviewed separate halves of the total data set for inclusion. A portion of total data abstracted (15\%) was verified for inter-rater reliability by the principal investigator (CK). Demographic and descriptive data are reported as means with standard deviations or as absolute values with percentages as appropriate.

Blood traceability and usage data were manually extracted from transfusion services paper documentation and transcribed into a standardized collection spreadsheet (Excel, Microsoft). Data from consecutive records from May 6, 2014 to October 10, 2017 were available from the Calgary, Alberta base. Blood that was used, wasted, or returned to circulation was tracked.

University of Calgary's Research Ethics Review Board approved the study. Waiver of consent was obtained given all data were collected as part of ongoing quality assurance measures and entirely de-identified.

\section{Setting}

Shock Trauma Air Rescue Society (STARS) is a critical care HEMS provider that supports six bases in Western 
Canada (Figure 1). STARS' mission philosophy is to deliver safe, rapid, highly specialized emergency transport to critically ill and injured patients in the prehospital environment. Two pilots, a critical care nurse, and a critical care paramedic staff each flight. Transport physicians (TP) are on-call at all times to provide online medical support and may accompany the air medical crew (AMC) on transports to provide direct patient care as needed. Scene calls $(35 \%)$ and inter-facility transports $(65 \%)$ make up the more than 3,000 missions flown annually across the organization. Since 2013, STARS aircraft (BK-117 and AW-139 helicopters) have carried 2 units of $\mathrm{O}$ negative packed red blood cells (pRBCs) in a temperature-controlled cooler. The program first started in Regina, Saskatchewan, and has gradually expanded to all six bases. Prior to blood on board, either the sending facility would provide blood products, if available, or our local transfusion services would prepare blood products for AMC to pick up prior to departure (inter-facility transports only). This resulted in depletion of rural and remote blood products, which may take an extended time to restock, or significant delay to both patient transport and initiation of patient care by AMC.

\section{Blood storage system}

The successful development of our blood on board program required that $\mathrm{pRBCs}$ be readily available and safely stored outside of a blood bank, while minimizing wastage of this valuable resource. In consultation with our local transfusion services, we sought a storage device that was cost-effective, reasonably lightweight, portable, and small enough to fit in the confined storage space of a helicopter.

The Credo thermal packaging box (Series 4-496, Plymouth, Minnesota, USA) is capable of maintaining payload temperatures between $1^{\circ} \mathrm{C}$ and $6^{\circ} \mathrm{C}$ for up to 96 hours, in ambient temperatures of up to $36^{\circ} \mathrm{C}$. At just over $21 \mathrm{~L}$ and only $5 \mathrm{~kg}$, this device fits the space constraints inside STARS aircraft. The coolers require a basic preconditioning process according to the manufacturer's instructions (Figure 2) prior to each packing and are then ready for transport and clinical use. The total cost of the thermal packaging box, including thermal panelling and carrier bag, is $\$ 440 \mathrm{CAD}$ with a 5 -year expiry. The cooler system was inspected for weight, balance, and secure stowage inside the aircraft prior to being operational.

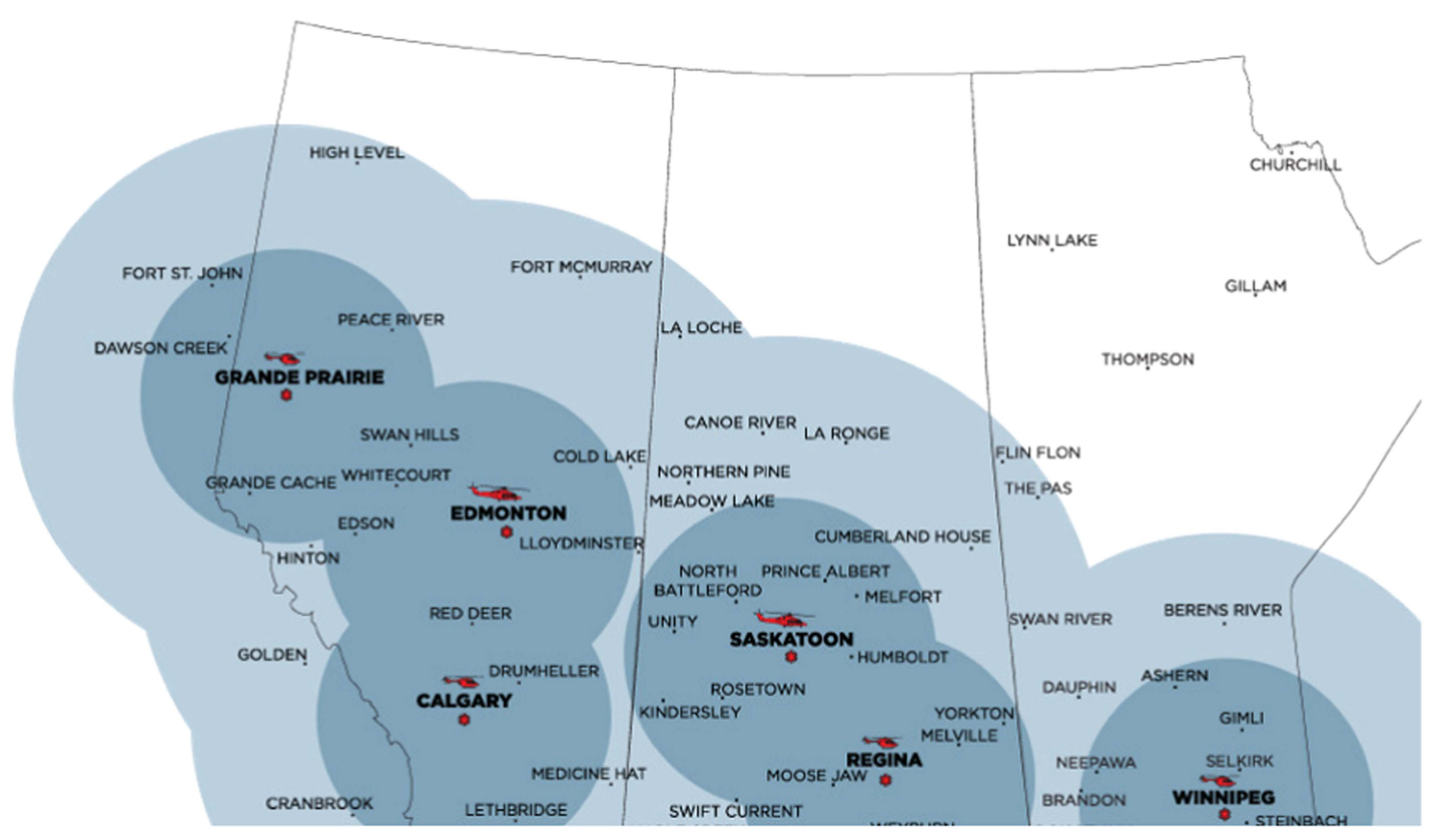

Figure 1. STARS bases with helicopter type, 1- and 2-hour flight circles depicted. 


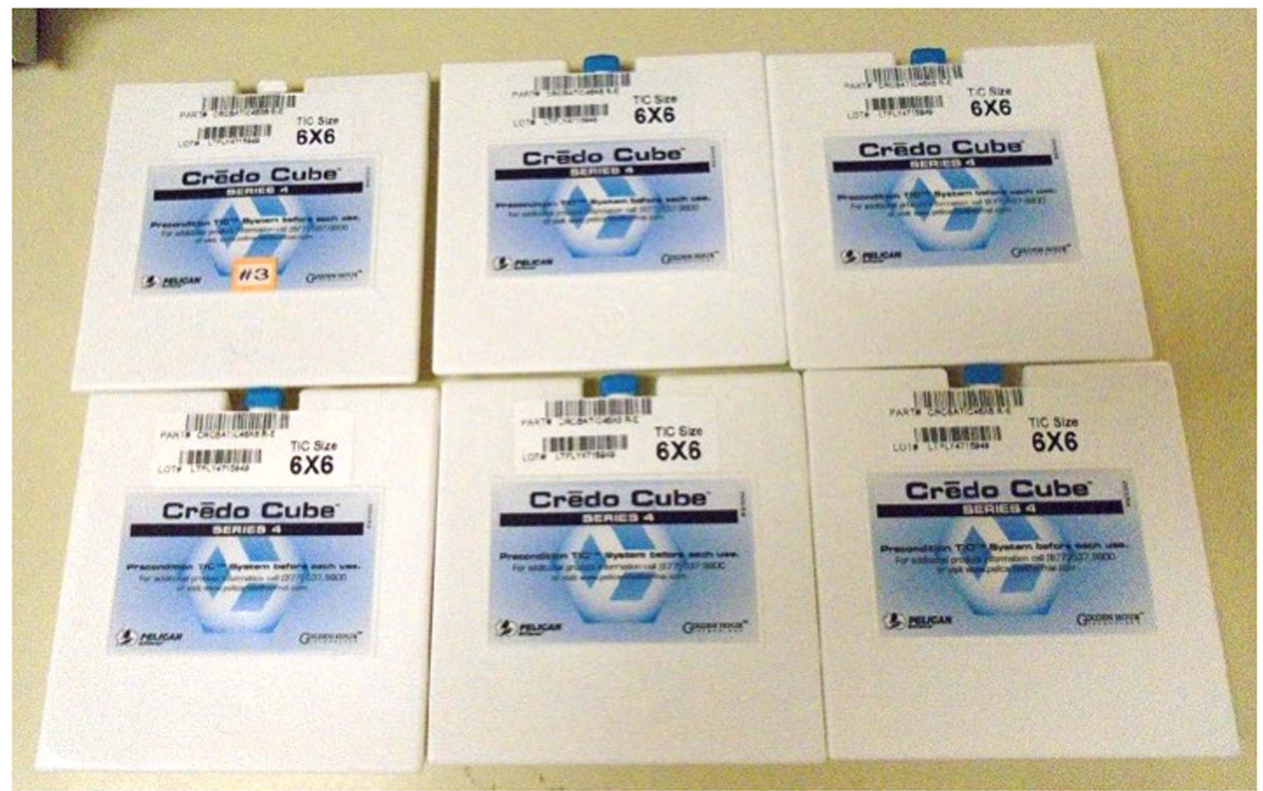

Figure 2. Phase-change panels are stored at $-20^{\circ} \mathrm{C}$ and conditioned at room temperature for 25 minutes prior to packing.

To monitor the internal temperature, each cooler contains a continuous electronic temperature recorder (LogTag Recorders TRID30-7, Westfield, New Jersey, USA). The device records time-stamped data for extraction and also provides a visual alert if the internal temperature has deviated from the required range. The coolers are monitored and maintained between $1^{\circ} \mathrm{C}$ and $6^{\circ} \mathrm{C}$ in accordance with the Western Canada Diagnostic Accreditation Alliance, Canadian Standards Association, and Canadian Society for Transfusion Medicine recommendations. ${ }^{16}$

The boxes are routinely exchanged at $72-96$ hour intervals (depending on the base), and unused blood is returned to general circulation via transfusion services if appropriate internal temperatures have been continuously maintained. Each box is stored securely on the helicopter, or in the AMC equipment staging area if outside ambient temperature is greater than $25^{\circ} \mathrm{C}$. Because dispatches often occur with limited clinical information and the risk of being rerouted to another call, AMC brings the blood box on every mission. AMC daily checks consist of ensuring that the blood box is sealed, checking when the next blood box exchange is due, and ensuring that the transfusion paperwork is present.

\section{Administration process}

After meticulous attention to hemorrhage control, AMC may consider blood product administration, a decision that must be discussed with the on-call TP. Other available hemorrhage control measures include tranexamic acid, pelvic binders, extremity tourniquets, and wound dressings, where appropriate. General guidelines for $\mathrm{AMC}$ to request transfusion have been developed internally (Box 1). In alert patients and where appropriate, verbal consent is obtained and documented in the ePCR. Once an order for blood has been provided by the TP, the blood box seal is broken and contents inspected to ensure that no temperature deviation has occurred, the donor blood type is appropriate, and the blood is not expired, leaking, or otherwise compromised. The blood is not administered if any visual inspection and/or quality control checks are abnormal. Rarely, transfusion services may dispense $\mathrm{O}$ positive blood in the event of $\mathrm{O}$ negative shortage. The blood cooler and units are clearly flagged, and AMC must notify the on-call TP of the $\mathrm{O}$ positive pRBCs so potential contraindications (i.e., pregnancy, female of childbearing age) may be discussed prior to the decision to transfuse.

New blood administration education for the crew was not required, as all STARS AMC have extensive critical care backgrounds with experience in transfusion of blood products, and all aircraft are staffed by a nurse and paramedic at all times. Nevertheless, all AMC completed STARS-specific training modules to ensure familiarity with the Credo equipment and protocols, as well as the scheduled and unscheduled exchange protocols. 
- Persistent hemorrhagic shock despite hemorrhage control measures and crystalloid infusion

- Hemorrhagic shock = persistent tachycardia despite analgesia, hemorrhage control, and a trial of crystalloid fluids; or hypotension (SBP $<100 \mathrm{~mm} \mathrm{Hg}$ ) despite hemorrhage control and a crystalloid trial

- Estimated blood loss greater than $20 \%$ of total blood volume

- Hemoglobin less than or equal to $70 \mathrm{~g} / \mathrm{L}$ in any transported patient symptomatic from his or her anemia

- Hemoglobin less than $80 \mathrm{~g} / \mathrm{L}$ with ischemic heart disease or other cardiac compromise and symptomatic from patient's anemia

- Hemoglobin less than $90 \mathrm{~g} / \mathrm{L}$ and ongoing significant losses are anticipated (e.g., massive gastrointestinal bleeding, retroperitoneal hemorrhage, intra-thoracic hemorrhage, or intra-abdominal hemorrhage)

Once the blood box is opened, both units are typically given to the patient. Blood is administered through a portable fluid warmer (enFlow, Vyaire Medical, USA) at rates up to $200 \mathrm{cc} /$ minute. Should only one unit be administered (e.g., pediatric trauma), the second unit is kept in the monitored cooler and returned to the receiving facility's blood bank where temperature data are assessed and the unit returned to circulation if appropriate. In the event that the AMC arrives at the receiving destination prior to the second unit being administered, the second unit can be initiated by the AMC during transfer of care at the discretion of the receiving physician. Appropriate transfusion patient monitoring is handed over to the accepting team. Transfusion Services is notified as soon

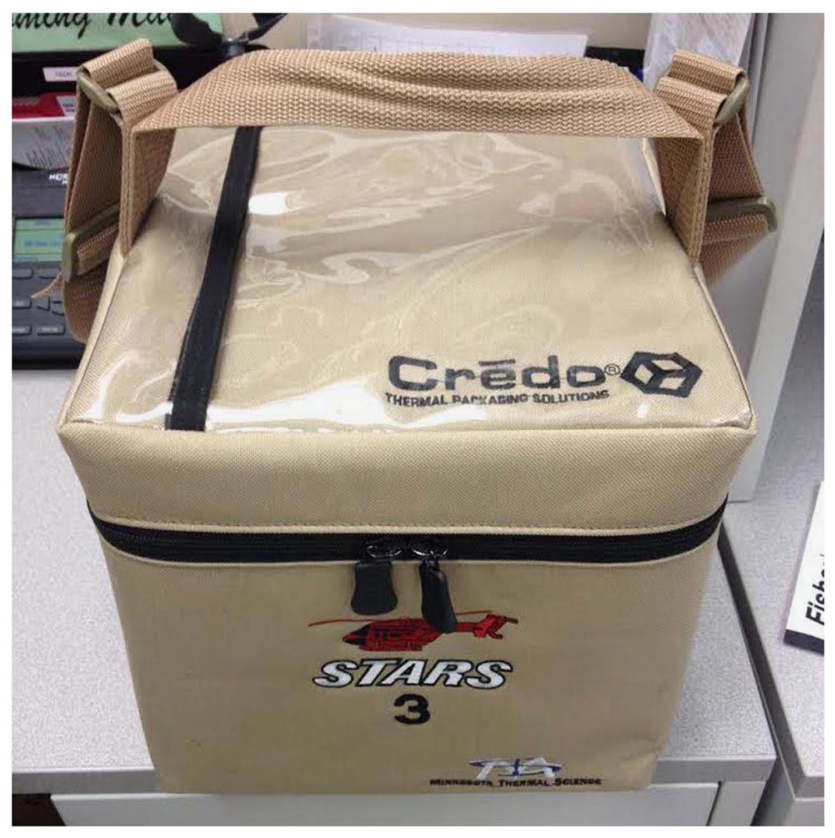

Figure 3. Each blood box is prepared and sealed by transfusion services personnel with two units of $O$ negative pRBCs and the temperature logger inside. as possible after opening of the blood box, so that a timely replacement box can be conditioned, packed, and prepared (Figure 3 ). This process generally requires a 30-minute lead time. In addition, any adverse reaction felt to be related to the blood product requires prompt discontinuation and treatment, as well as event reporting to transfusion services as per our standard operating procedure.

Standard transfusion medicine documentation is completed for every pRBC unit administered or returned to the blood bank. The AMC documents all patient-related data and care after every mission in an ePCR that is stored in a searchable database.

\section{Quality assurance process}

As part of an ongoing quality assurance process, all records are formally reviewed first by a peer and subsequently by the base medical director or designate to ensure completeness of documentation and appropriateness of blood transfusion and clinical care. Each base engaged in their own internal quality control processes as blood on board was launched locally. In addition, regular communications with the local blood bank services personnel identified site-specific challenges in the early months of program establishment. In addition to the routine ePCR review, front-line staff are encouraged to submit safety reports detailing any procedural difficulty or safety concern identified during the course of prehospital transfusion or related care. During the first year of blood on board at the Winnipeg base, 11 such incidents were reported (Box 2).

Root causes of delayed blood bank notifications could generally be attributed to specific communication challenges arising during complex care of unstable patients. These included TPs otherwise engaged in patient care or crew communications, and unexpected 
- Absence of necessary Y-tubing during ground transport by STARS (1)

- Missing security seal on new Credo box received from blood bank (3)

- Crew dispatched on second mission with old empty Credo box still on board; no communication to blood bank (2)

- Record of transfusion returned to blood bank without patient demographics (1)

- Delayed recognition of incomplete scheduled Credo box exchange due to Boxing Day Blizzard (1)

- Delayed notification of blood bank regarding need for unscheduled Credo box exchange after use in patient care (3)

change in the receiving facility due to patient arrest during a ground transport transfer. Each report was addressed with specific changes to crew/TP standard work, modification of protocols, and communication with blood bank and courier personnel. For example, the safety report regarding a lack of necessary Y-tubing led to an organization wide standardization in kit layout and handling.

\section{RESULTS}

\section{Demographics}

During the study period, 9,695 patients were transported organization wide, and 9,421 were excluded because they did not meet eligibility criteria, leaving a final sample size of 274 (Figure 4). Patient demographics and mission types are described in Table 1. The blood box was used in 274 patients $(62.9 \%$ of all patients transfused), an average of 68 times per year (Table 2). A total of 463 blood box units were administered over the time period, and the majority of patients $(69.0 \%)$ received both units of pRBCs while

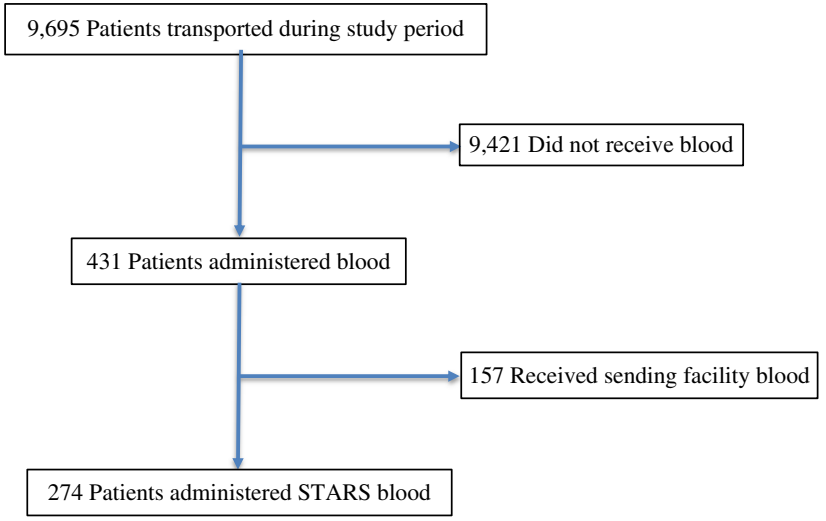

Figure 4. Study patient selection process. under STARS care. There was variation in frequency of blood box use between bases from 1.8 uses per 100 patients (Regina, Saskatchewan) to 5.2 uses per 100 patients (Winnipeg, Manitoba). The majority of patients are male $(68.2 \%)$. Trauma was the most common diagnosis $(74.1 \%)$. The median age was 44 years old with $32(11.7 \%)$ pediatric patients (age less than 18 years). Of all patients, 241 (88.0\%) survived to hospital arrival. There was substantial agreement between data abstractors $(\kappa=0.73)$.

\section{Blood usage}

From May 6, 2014 to October 10, 2017, Calgary lab services dispensed a total of 898 units of pRBCs with $100 \%$ traceability. Eleven units $(1.2 \%)$ were wasted

\begin{tabular}{lr|}
\hline \multicolumn{2}{|l|}{ Table 1. Basic demographics and mission types by site } \\
\hline Characteristic & \multicolumn{1}{l}{ Value } \\
\hline Male sex $-\mathrm{n}(\%)$ & $187(68.2)$ \\
Median age $-\mathrm{yr}(\mathrm{SD})$ & $44(23.1)$ \\
Mean age $-\mathrm{yr}(\mathrm{SD})$ & $44.7(23.1)$ \\
IQR age $-\mathrm{yr}$ & 37.8 \\
Diagnosis $-\mathrm{n}(\%)$ & \\
Medical & $71(25.9)$ \\
Trauma & $203(74.1)$ \\
Mission type - $\mathrm{n}(\%)$ & \\
Scene call & $137(50)$ \\
Inter-facility & $137(50)$ \\
Mission type by site, scene call - $\mathrm{n}$ (\%) & \\
Calgary & $32(39.5)$ \\
Edmonton & $29(43.9)$ \\
Grande Prairie & $7(46.7)$ \\
Saskatoon & $18(48.6)$ \\
Regina & $8(29.6)$ \\
Winnipeg & $43(89.6)$ \\
\hline IQR =interquartile range. &
\end{tabular}




\begin{tabular}{|c|c|c|c|c|}
\hline Base & $\begin{array}{l}\text { Date of } \\
\text { inception }\end{array}$ & $\begin{array}{l}\text { Total patient contacts during } \\
\text { study period, } \mathrm{n}\end{array}$ & $\begin{array}{l}\text { Blood box utilization, } \\
\text { total } n(\%)\end{array}$ & $\begin{array}{l}\text { Blood box utilization, per } 100 \text { patient } \\
\text { contacts }(n / 100)\end{array}$ \\
\hline & \multicolumn{4}{|c|}{ Total - 274} \\
\hline Calgary, Alberta & May 6, 2014 & 1,987 & 81 (29.6) & 4.1 \\
\hline Edmonton, Alberta & $\begin{array}{l}\text { December 9, } \\
2014\end{array}$ & 1,571 & $66(24.1)$ & 4.2 \\
\hline Grande Prairie & $\begin{array}{l}\text { February 10, } \\
2015\end{array}$ & 556 & $15(5.5)$ & 2.7 \\
\hline $\begin{array}{l}\text { Saskatoon, } \\
\text { Saskatchewan }\end{array}$ & $\begin{array}{l}\text { September 6, } \\
2014\end{array}$ & 1,067 & 37 (13.5) & 3.5 \\
\hline $\begin{array}{l}\text { Regina, } \\
\text { Saskatchewan }\end{array}$ & $\begin{array}{l}\text { October 1, } \\
2013\end{array}$ & 1,519 & $27(9.8)$ & 1.8 \\
\hline $\begin{array}{l}\text { Winnipeg, } \\
\text { Manitoba }\end{array}$ & $\begin{array}{l}\text { January 18, } \\
2016\end{array}$ & 913 & $48(17.5)$ & 5.3 \\
\hline
\end{tabular}

over the time period and 131 (14.6\%) administered. The remaining $756(84.2 \%)$ units were returned to transfusion services inventory. All units were wasted due to deviation outside the safe temperature range. Therefore, $99.0 \%$ of unused units were returned back to circulation for future use. There were no reports of adverse reactions related to blood products.

\section{DISCUSSION}

\section{Interpretation}

Our results support the successful introduction of the first HEMS blood transfusion program in Canada. Blood is a precious resource that is often in short supply. ${ }^{17}$ In Calgary, just $1.2 \%$ of units have been wasted since May, 2014, and all of them were within the first year. These pRBCs deviated outside the allowable temperature range due to problems with cooler conditioning and the box being left open while only one unit was used. Our AMC and transfusion services have become more familiar over time with the storage and stewardship processes, demonstrating the successful quality assurance practices used. The vast majority of unused pRBCs make their way back into the local blood inventory for future use. We have had similar success since the introduction of the program at the other STARS bases based on individual internal audits. In addition, this program often prevents the consumption of facility-based pRBCs in rural and remote communities. For example, if STARS rendezvous at a rural hospital for an injured patient who requires blood product administration, the blood box can be used rather than the rural blood products, which are often limited and may take an extended time to be restocked. In addition, for patients with significant transfusion requirements, which may quickly overwhelm a rural facility's blood supply, blood on board provides a bridge to tertiary care.

Our blood box was mainly used in injured male patients. Interestingly, blood on board was used equally in scene calls and inter-facility transports. This is likely due to STARS arranging rendezvous at rural hospitals with ground emergency medical services (EMS) providers prior to the transport of patients to tertiary care. The Winnipeg, Manitoba, base administered blood to a much higher proportion of scene calls compared with other bases. The infrastructure in Manitoba comprises sparse coverage of rural hospitals and a rural EMS system with primarily basic life support capabilities, which we believe contributes to this outlying value.

Another hypothesis-generating finding is the discrepancy between blood usage per month between bases. Calgary, Edmonton, and Winnipeg used the blood box more frequently than Saskatoon, Regina, and Grande Prairie. These discrepancies may be due to differences in supporting community hospital and EMS infrastructure, differences in practice, or different patient injury and illness patterns. Further investigative work is required.

\section{Prior studies}

At this time, available data for prehospital blood transfusion are limited but suggest improvement in early patient outcomes without convincing evidence of 
overall survival improvements. ${ }^{18-20}$ Recently, a large retrospective cohort study of combat medical evacuations in Afghanistan described significant improvement in both 24-hour and 30-day survival when prehospital blood was administered. ${ }^{21}$ However, selection bias for more critically ill patients might exist, making a true survival benefit difficult to demonstrate. As well, a recent multicentre, cluster-randomized trial of thawed plasma versus standard care in a prehospital civilian population showed improvement in 30-day mortality among trauma patients at risk for hemorrhagic shock. $^{22}$ A proportion of patients in each study arm also received pRBCs lending consideration for broadening the type of blood products carried on board. There are at least two randomized controlled studies ongoing that may elicit more robust information, ${ }^{23-24}$ including a previously described multicentre randomized controlled trial of prehospital blood transfusion in the $\mathrm{UK}^{25}$

Using blood on board has enhanced our ability to provide optimal and timely care to critically ill and injured patients. STARS operates over a large geographical area, which results in long patient transport times. Previously reported average times from injury to receiving hospital arrival for scene and inter-facility missions are 171 and 224 minutes, respectively. ${ }^{26}$ Prehospital crystalloid resuscitation is associated with an increase in mortality and coagulopathy. ${ }^{27-28}$

\section{Limitations and strengths}

There are several limitations to this study. STARS operates across multiple provinces and jurisdictions, which makes uniform access to hospital discharge data, as well as blood bank utilization a significant challenge. Patient-oriented outcomes such as neurologically intact survival, overall mortality, and patient safety were not able to be assessed given the quality improvement and program evaluation study design. Definitive numbers on blood wastage from locations other than Calgary, Alberta could not be obtained, though they were tracked by individual transfusion services as part of their own quality assurance. In addition, appropriateness of blood transfusion and potential missed cases was not assessed, although each incident of transfusion is first reviewed with a TP oncall. Each mission is also peer reviewed by a senior AMC and medical director with feedback provided directly to the practitioners involved.
The strength of this manuscript is in the pragmatic, simple approach described in creating a sustainable prehospital blood transfusion program. Our robust stewardship process leads to very minimal wastage of blood products by returning the bulk of unused blood to the general circulation. Ongoing quality improvement initiatives help strengthen the process.

\section{Clinical implications}

Our results provide the groundwork for other prehospital agencies to develop a similarly sustainable blood transfusion program. The stewardship and standard work processes can be replicated with minimal wastage of blood products. Although patient-oriented outcomes were not described, ongoing work is being done in this area within our organization.

\section{Research implications}

Future considerations should focus on defining characteristics of this complex patient population as well as the appropriateness of transfusion to describe a specific population that may benefit from prehospital blood. In addition, patient-oriented outcomes such as neurologic recovery, overall mortality, and safety of transfusion should be evaluated, because the overall benefit of prehospital transfusion is not known.

\section{CONCLUSION}

The STARS blood on board program supports the provision of timely access to blood products, when indicated, to critically ill and injured patients in the prehospital environment. The success of our program relies on the processes governing safe storage, administration, and stewardship of blood products. Close collaboration with transfusion services was instrumental to this achievement. In addition, staff training and cost were minimal. Further work is required to assess the detailed characteristics, in-hospital management, and clinically relevant outcomes of this patient cohort.

Acknowledgements: We thank Calgary Lab Services, Calgary, $\mathrm{AB}$, and Diagnostic Services Manitoba, Manitoba Blood Bank, Winnipeg, MB for their work in this study.

Competing interests: None declared. 


\section{REFERENCES}

1. Public Health Agency of Canada analysis of data from the Hospital Morbidity Database. Canadian Institute for Health Information. The cost of injury in Canada. Toronto, ON: Parachute; 2015.

2. Kauvar DS, Wade CE. The epidemiology and modern management of traumatic hemorrhage: US and international perspectives. Crit Care 2005;9(Suppl 5):S1-9.9, doi:10.1186/cc3779.

3. Powell EK, Hinckley WR, Gottula A, et al. Shorter times to packed red blood cell transfusion are associated with decreased risk of death in traumatically injured patients. 7 Trauma Acute Care Surg 2016;81:458-62, doi:10.1097/ TA.0000000000001078.

4. Chatrath V, Khetarpal R, Ahuja J. Fluid management in patients with trauma: restrictive versus liberal approach. $\mathcal{F}$ Anesthesiol Clin Pharmacol 2015;31:308-16, doi:10.4103/0970-9185.161664.

5. Ball C. Damage control resuscitation: history, theory and technique. Can 7 Surg 2014;57:55-60, doi:10.1503/ cjs.020312.

6. Cotton BA, Guy JS, Morris JA Jr, Abumrad NN. Cellular, metabolic, and systemic consequences of aggressive fluid resuscitation strategies. Shock 2006;26:115-21, doi:10.1097/01.shk.0000209564.84822.f2.

7. Rhee P, Koustova E, Alam HB. Searching for the optimal resuscitation method: recommendations for the initial fluid resuscitation of combat casualties. 7 Trauma 2003;54:S5262, doi:10.1097/01.TA.0000064507.80390.10.

8. Floccare DJ, Stuhlmiller DF, Braithwaite SA, et al. Appropriate and safe utilization of helicopter emergency medical services: a joint position statement with resource document. Prehosp Emerg Care 2013;17:4, 521-5, doi:10.3109/10903127.2013.804139.

9. Brown JB, Gestring ML, Guyette FX, et al. Helicopter transport improves survival following injury in the absence of time saving advantage. Surgery 2016;159(3): 947-59, doi:10.1016/j.surg.2015.09.015.

10. Andruszkow H, Lefering R, Frink M, et al. Survival benefit of helicopter emergency medical services compared to ground emergency medical services in traumatized patients. Crit Care 2013;17(3):R124, doi:10.1186/cc12796.

11. Cap AP, Pidcoke HF, DePasquale M, et al. Blood far forward: time to get moving! 7 Trauma Acute Care Surg 2015;78:S2-6, doi:10.1097/TA.0000000000000626.

12. O'Reilly DJ, Morrison JJ, Jansen JO, et al. Initial UK experience of prehospital blood transfusion in combat casualties. I Trauma Acute Care Surg 2014;77:S66-70, doi:10.1097/SHK.0000000000000569.

13. Lyon RM, Sausmarez E, McWhirter E, et al. Pre-hospital transfusion of packed red blood cells in 147 patients from a UK helicopter emergency medical service. Scand 7 Trauma Resusc Emerg Med 2017;25:12, doi:10.1186/s13049-017-0356-2.

14. Maher P, Utarnachitt R, Louzon MJ, et al. Logistical concerns for prehospital blood product use by air medical services. Air Med 7 2017;36:263-7, doi:10.1016/j.amj.2017.05.003.
15. Karl A, Pham T, Yanosky JD, Lubin J. Variability of uncrossmatched blood use by helicopter EMS programs in the United States. Prehosp Emerg Care 2016;20:688-94, doi:10.1080/10903127.2016.1182607.

16. Food and Drugs Act Blood Regulations. Canada Gazette, Part II, 147(22); 2013. Available at: http://www.gazette.gc. ca/rp-pr/p2/2013/2013-10-23/html/sor-dors178-eng.html (accessed October 30, 2017).

17. Canadian Blood Services Statements. Update: critical need for donors continues as Canada's supply of universal blood type dips beneath two days; 2017. Available at: https://blood.ca/en/ media/update-critical-need-donors-continues-canadas-supplyuniversal-blood-type-dips-beneath-two-days (accessed November 10, 2017).

18. Holcomb JB, Donathan DP, Cotton BA, et al. Prehospital transfusion of plasma and red blood cells in trauma patients. Prehosp Emerg Care 2015;19(1):1-9, doi:10.3109/10903127.2014.923077.

19. Potter DD, Berns KS, Elsbernd TA, Zietlow SP. Prehospital use of blood and plasma in pediatric trauma patients. Air Med f 2015;34(1):40-3, doi:10.1016/j.amj.2014.07.037.

20. Smith IM, James RH, Dretzke J, Midwinter MJ. Prehospital blood product resuscitation for trauma: a systematic review. Shock 2016;46(1):3-16, doi:10.1097/ SHK.0000000000000569.

21. Shackelford SA, Del Junco DJ, Powell-Dunford N, et al. Association of prehospital blood product transfusion during medical evacuation of combat casualties in Afghanistan with acute and 30-day survival. 7AMA 2017;318(16):1581-91, doi:10.1001/jama.2017.15097.

22. Sperry JL, Guyette FX, Brown JB, et al. Prehospital plasma during air medical transport in trauma patients at risk for hemorrhagic shock. N Engl 7 Med 2018;379(4):315-26, doi:10.1056/NEJMoa1802345.

23. Rehn M, Weaver A, Brohi K, et al. Effect of pre-hospital red blood cell transfusion on mortality and time of death in civilian trauma patients. Shock 2018; epub, doi:10.1097/ SHK.0000000000001166.

24. Tourtier JP, Jost D, Sailliol A, Verret C. Pre-hospital administration of lyophilized plasma for post-traumatic coagulopathy treatment (PREHO-PLYO). 2017; Manuscript in Preparation. NCT02736812.

25. Smith IM, Crombie N, Bishop JR, et al. RePHILL: protocol for a randomized controlled trial of pre-hospital blood product resuscitation for trauma. Transfus Med 2017; epub, doi:10.1111/tme.12486.

26. Mrochuk M, ODochartaigh D, Chang E. Rural trauma patients cannot wait: tranexamic acid administration by helicopter emergency medical services. Air Med 7 2015;34 (1):37-9, doi:10.1016/j.amj.2014.09.004.

27. Maegele M, Lefering R, Yucel N, et al. Early coagulopathy in multiple injury: an analysis from the German Trauma Registry on 8724 patients. Injury 2007;38(3):298-304, doi:10.1016/j.injury.2006.10.003.

28. Haut ER, Kalish BT, Cotton BA, et al. Prehospital intravenous fluid administration is associated with higher mortality in trauma patients: a National Trauma Data Bank analysis. Ann Surg 2011;253(2):371-7, doi:10.1097/SLA.0b013e318207c24f. 